\title{
Characterization of Rhizoctonia spp. Causing Root and Stem Rot of Miniature Rose
}

A. Priyatmojo, United Graduate School of Agricultural Science, Gifu University, Yanagido 1-1, Gifu 501-1193, Japan; Y. Yotani and K. Hattori, Buromeria Gifu, Hirakara 1295, Kaizu, Gifu 503-0651, Japan; and K. Kageyama and M. Hyakumachi, Laboratory of Plant Disease Science, Faculty of Agriculture, Gifu University, Yanagido 1-1, Gifu 501-1193, Japan

\begin{abstract}
Priyatmojo, A., Yotani, Y., Hattori, K., Kageyama, K., and Hyakumachi, M. 2001. Characterization of Rhizoctonia spp. causing root and stem rot of miniature rose. Plant Dis. 85:1200-1205.

Root and stem rot of miniature rose (Rosa hybrida L.) was observed in commercial glasshousegrown roses in Gifu prefecture, Japan, during the summer and fall of 1997 and 1998. One hundred and fifty-three isolates of Rhizoctonia spp. were obtained from infected roots and stems. Of the 153 isolates, 9 had binucleate and 144 had multinucleate vegetative hyphal cells. Binucleate Rhizoctonia failed to anastomose with tester isolates of anastomosis groups (AG)-A through -S (not including AG-J and AG-M). Of 144 isolates identified as $R$. solani, $83.3 \%$ were AG 2-2 IIIB and 16.7\% were AG 4 HG-I. Five isolates from each group caused severe rot and mortality on cuttings during rooting. Pathogenicity of Rhizoctonia spp. varied on three different ages of miniature roses cv. Silk. Isolates of AG 4 HG-I caused root and stem rot and mortality on 15-, 25-, and 40-day-old plants, whereas isolates of AG-2-2 IIIB caused root and stem rot and mortality on 15- and 25-day-old plants, but light root rot on 40-day-old plants. Isolates of binucleate Rhizoctonia caused root and stem rot and mortality only on 15-day-old plants.
\end{abstract}

Additional keywords: Ceratobasidium, hyphal fusion, RFLP analysis, Thanatephorus cucumeris

Miniature potted roses are among the best selling flowering potted plants in Japan. Many attempts are being made to improve the quality and increase the production of these attractive flowering plants. One of the constraints on rose production is the occurrence of fungal disease. During the summer and fall of 1997 and 1998, a root and stem rot disease was observed in commercially grown miniature roses in Gifu prefecture, Japan. Infected roots and stems turned dark brown or black (Fig. 1); the upper part of the plant showed a wilt symptom because roots and stems suffered from severe rot. Plants died a few days later due to disruption of translocation of water and nutrients. Mycelia were often found on roots and stems near the soil surface. Disease was frequently observed on young plants. Rhizoctonia spp. were consistently isolated from the diseased roots and stems of miniature roses. Although Rhizoctonia spp. have been re-

Corresponding author: M. Hyakumachi

E-mail: hyakumac@cc.gifu-u.ac.jp

Current address of A. Priyatmojo: Department of Entomology and Plant Pathology, Faculty of Agriculture, Gadjah Mada University, Yogyakarta 55281, Indonesia.

Accepted for publication 30 July 2001.

Publication no. D-2001-0910-02R

(C) 2001 The American Phytopathological Society ported as a major plant-pathogenic fungus causing severe economic damage to many species of ornamental plants, occurrence of Rhizoctonia spp. on miniature rose has not been reported to date $(5,12)$.

The genus Rhizoctonia represents many fungi which are mutual symbionts as well as pathogens $(2,21,29)$. Pathogenic Rhizoctonia spp. attack and cause severe diseases on many economically important plants $(1,20)$. Isolates of Rhizoctonia vary greatly in their colony morphology, growth characteristics, and pathogenicity toward plants $(1,21)$. However, most Rhizoctonia spp. can be classified into uninucleate, binucleate, or multinucleate groups, based on the number of nuclei in vegetative hyphal cells $(11,29)$.

At present, $R$. solani is considered a species complex rather than a single species $(1,3)$. Attempts have been made to divide the species complex into more homogeneous groups. The most widely used method to separate $R$. solani is based on hyphal anastomosis. Hyphae of isolates will only anastomose each other if they are within the same anastomosis group (AG) $(3,7,29)$. Recently, $R$. solani was divided into 14 AGs designated as AG 1 through 13 and bridging isolate $(\mathrm{BI})$ group $(8,29)$. Isolates belonging to AG BI have the ability to anastomose with members of other AGs (7). Binucleate Rhizoctonia spp. have been divided into 19 AGs designated as AG-A through -S (22-24) but the tester isolate of AG-M is lost (29).
Some AGs of binucleate Rhizoctonia spp. and $R$. solani are further divided into subgroups based on cultural morphology, nutritional requirements, temperature effect on growth, host specificity, frequency of hyphal anastomosis, and pathogenicity $(21,29)$. Present methods of distinguishing subgroups employ biochemical (30) and molecular techniques $(16,28)$. Binucleate Rhizoctonia AG-B has been subdivided into AG-Ba, -Bb, and -Bo subgroups (29). Binucleate Rhizoctonia AG-D has been subdivided into D (I) and D (II) subgroups (31). R. solani AG 2 has been subdivided into AG 2-1, 2-2, and 2-3 subgroups and AG 2-2 is further subdivided into IIIB, IV, and LP ecological types $(13,29)$. $R$. solani AG 4 has been subdivided into subgroups HG-I and HG-II according to sclerotial form and DNA base sequence homology (16).

The objective of the present study was to characterize Rhizoctonia spp. obtained from infected roots and stems of miniature roses. Isolates were studied for nuclear condition, hyphal anastomosis, cultural appearance, thiamine requirement, effect of temperature on mycelial growth, and pathogenicity. Isolates of $R$. solani AG 4 were detected; therefore, restriction fragment length polymorphism analysis of the ribosomal DNA-internal transcribed spacer (RFLP of rDNA-ITS) was also performed to confirm whether they belong to subgroup HG-I or HG-II. A preliminary report of this investigation has been published (27).

\section{MATERIALS AND METHODS}

Isolation and culture maintenance. Miniature rose samples were obtained from commercial glasshouse-grown roses in Gifu prefecture, Japan. Symptomatic roots and stems were washed thoroughly in running tap water for $30 \mathrm{~min}$ to remove adhered soil particles, air dried, then cut into 5 -mm pieces. Roots and stems were surface disinfected with $0.5 \%$ sodium hypochlorite solution for $2 \mathrm{~min}$ and rinsed three times with sterile distilled water. Pieces of root and stem were dried separately on sterilized filter paper (Whatman no. 1), placed on petri dishes containing water agar acidified $(\mathrm{pH} 4.5)$ with $10 \%$ lactic acid (AWA), and incubated at $25^{\circ} \mathrm{C}$ in the dark. After 2 to 3 days, cultures were examined microscopically for hyphal char- 
acteristic typical of Rhizoctonia spp. (26). Rhizoctonia-like fungi were hyphal tipped and subcultured onto AWA to avoid culture contamination. Isolates were transferred to test tube slants of $2 \%$ potato dextrose agar (PDA) and maintained at $25^{\circ} \mathrm{C}$. Pure cultures were stored in PDA slant tubes or on sterile barley grain at $4^{\circ} \mathrm{C}$.

Nuclear condition. Single 7-mmdiameter disks of 2- to 3-day-old cultures of Rhizoctonia spp. growing on PDA were transferred to clean glass slides which had been dipped in $99.5 \%$ ethanol and flamed before use. Inoculated glass slides were incubated in a moist chamber at $25^{\circ} \mathrm{C}$ in the dark. A drop of safranin $\mathrm{O}$ and $3 \%$ $\mathrm{KOH}$ (4) was placed directly in the mycelium of 1- to 2-day-old cultures. Twentyfive cells of each isolate were examined for nuclei at $\times 400$ magnification using bright field microscopy.

AG determination. AG identities were determined by using the glass-slide technique (15). Single 7-mm-diameter disks were cut from the perimeter of a 2- to 3day-old colony on PDA and placed on a clean glass slide. Tester isolates of binucleate Rhizoctonia AG-A through AG-S (not including AG-J due to lack of the tester isolates in our collection) or tester isolates of $R$. solani AG 1 through 11, 13, and AGBI were placed 3 to $4 \mathrm{~cm}$ away from each tested isolate. Slides were put in a moist chamber and incubated at $25^{\circ} \mathrm{C}$ for 24 to $48 \mathrm{~h}$ in the dark. Excess moisture was wiped from the bottom of the slide. When the hyphae from the two disks were overlapping, they were stained with safranin $\mathrm{O}$ and $3 \% \mathrm{KOH}$ and examined microscopically to determine anastomosis reaction (7).

Cultural appearance. Single 7-mm-diameter mycelial disks from the margins of actively expanding young cultures on PDA placed in the center of $9-\mathrm{cm}$ petri dishes containing 2\% PDA or Czapek solution agar were incubated at $25^{\circ} \mathrm{C}$ in the dark. Cultures were evaluated after 25 days of incubation.

Hyphal growth rates. Radial growth of Rhizoctonia spp. was determined at 5, 10, $15,20,25,28,30$, and $35^{\circ} \mathrm{C}$. A single $7-$ mm-diameter mycelial disk from the margin of a 2- to 3-day-old colony was transferred to PDA in a petri dish. Measurements were taken $12 \mathrm{~h}$ after incubating petri dishes to allow the diffusion of temperature to agar. Colony radius was measured at 24-h intervals until the colony reached the edge of the petri dishes. Treatments were replicated three times and the experiment was repeated twice.

Thiamine requirements. The effect of thiamine on growth of Rhizoctonia spp. was examined with a basal medium of glucose-asparagine (GA) containing $10 \mathrm{~g}$ of D-glucose, $2 \mathrm{~g}$ of L-asparagine, $0.5 \mathrm{~g}$ of $\mathrm{MgSO}_{4} \cdot 7 \mathrm{H}_{2} \mathrm{O}, 1 \mathrm{~g}$ of $\mathrm{KH}_{2} \mathrm{PO}_{4}, 0.2 \mathrm{mg}$ of $\mathrm{Fe}\left(\mathrm{NO}_{3}\right)_{3} \cdot 9 \mathrm{H}_{2} \mathrm{O}, 0.2 \mathrm{mg}$ of $\mathrm{ZnSO}_{4} \cdot 7 \mathrm{H}_{2} \mathrm{O}$, and $0.1 \mathrm{mg}$ of $\mathrm{MnSO}_{4} \cdot 7 \mathrm{H}_{2} \mathrm{O}$ per liter of distilled water (25). Fresh cultures of each isolate were grown separately on GA agar (GAA) for 2 to 3 days at $25^{\circ} \mathrm{C}$ in the dark. A single 7-mm-diameter mycelial disk of each isolate was then transferred to $40 \mathrm{ml}$ of GA medium amended with or without $10^{-5} \mathrm{M}$ thiamine hydrochloride in a $100-\mathrm{ml}$ Erlenmeyer flask and placed on a rotary shaker at $120 \mathrm{rpm}$ at $25^{\circ} \mathrm{C}$ for 2 weeks in the dark. Mycelia were vacuum filtered, rinsed several times with distilled water, and dried at $80^{\circ} \mathrm{C}$ for 2 days. Dry weights of mycelium of each isolate grown in basal medium with and without thiamine were compared. Treatments were replicated three times and the experiment was repeated twice. Isolates of AG 1-IC F-1 (prototrophic for thiamine) and AG 2-2 IIIB K2-8 (auxotrophic for thiamine) were included for comparison.

Polymerase chain reaction amplification and RFLP of rDNA-ITS analysis. RFLP of rDNA-ITS was employed to clarify whether isolates of $R$. solani AG 4 obtained from miniature rose belonged to subgroup HG-I or HG-II. Isolates of AG 4 HG-I R97 and HG-II Rh131 obtained from sugar beet were included for comparison. DNA extraction was conducted according to the procedure described by Lee and Taylor (17). The oligonucleotide primers ITS1: 5'-TCCGTAGGTGAACCTGCGG$3^{\prime}$ and ITS4: 5'-TCCTCCGCTTATTGA-
TATGC- $3^{\prime}$ were used to amplify ITS regions (34). Amplifications of the ITS sequence were conducted in a DNA Thermal Cycler (Perkin-Elmer Cetus Instruments, Norwalk, CT) using the reaction condition described by Toda et al (31). After extraction with chloroform, the amplification products were precipitated in $3 \mathrm{M}$ sodium acetate and $99.5 \%$ ethanol at $-80^{\circ} \mathrm{C}$ for 30 min, washed in $70 \%$ ethanol, dried under vacuum, and resuspended in $50 \mu \mathrm{l}$ of $\mathrm{TE}$ buffer $(10 \mathrm{mM}$ Tris- $\mathrm{HCl}, \mathrm{pH} 7.5$, and 1 mM EDTA). The ITS region from ribosomal DNA of each isolate was digested separately with restriction enzymes HinfI and HincII at $37^{\circ} \mathrm{C}$ for $6 \mathrm{~h}$ under buffer conditions suggested by the manufacturers (Takara Shuzo Co., Ltd., Kusatsu, Japan). Samples were electrophoresed into $2 \%$ NuSieve 3:1 agarose gel (FMC BioProduct, Rockland, MN) in Tris-borateEDTA buffer. A molecular marker size of 100 bp DNA ladder (Life Technologies, Inc., Gaithersburg, MD) was used as reference in each gel. Gels were stained with ethidium bromide and visualized under UV light.

Pathogenicity tests. In pathogenicity test 1 , the virulence of isolates of Rhizoctonia spp. on miniature rose cv. Silk was determined using 15-, 25-, and 40-day-old transplants (6 weeks of rooting). Five representative isolates from each group were

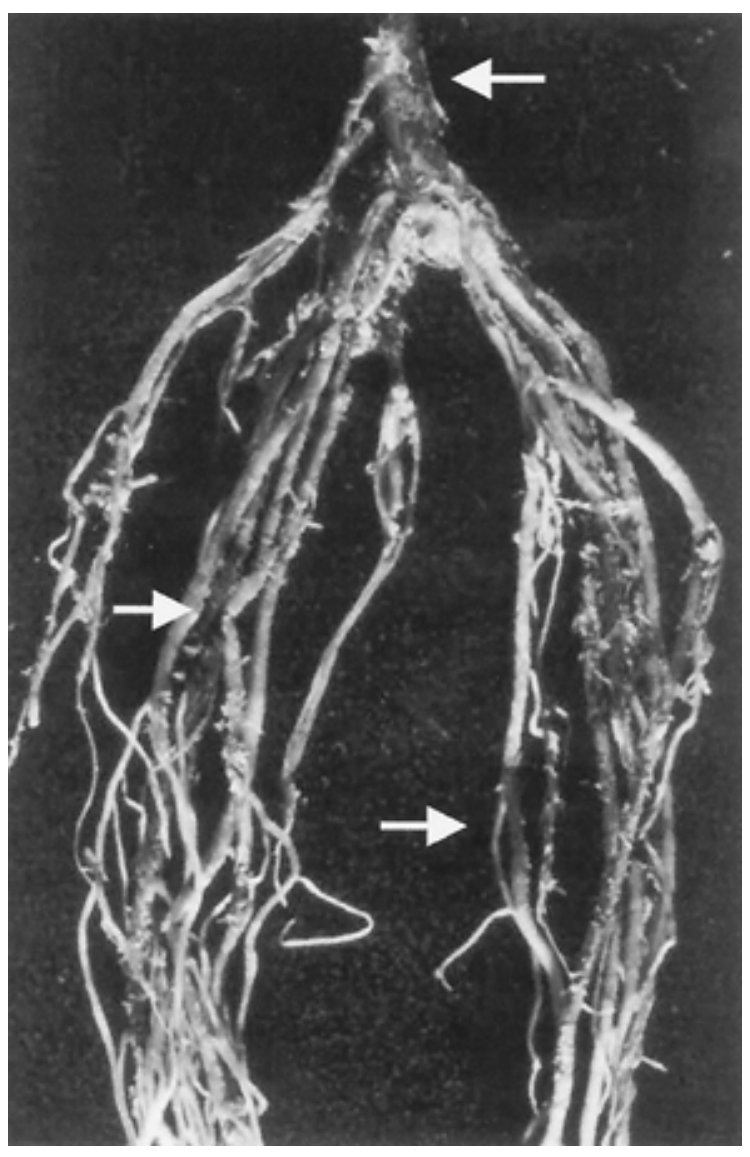

Fig. 1. Root and stem rot on miniature rose caused by Rhizoctonia spp. Arrows indicate severe root or stem rot parts. 
tested. Inoculum of Rhizoctonia spp. was prepared by growing each isolate in a 500-ml Erlenmeyer flask containing 100 $\mathrm{g}$ of barley grain and $100 \mathrm{ml}$ of distilled water. Flasks were sterilized at $121^{\circ} \mathrm{C}$ for $20 \mathrm{~min}$ and inoculated with three 7-mmdiameter mycelial disks of the isolates cut from the edges of 3-day-old Rhizoctonia spp. growing on PDA. Flasks were incubated at $25^{\circ} \mathrm{C}$ for 10 days in the dark and shaken regularly to aid uniform colonization. Infested barley grain was air dried for 1 week and stored at $4^{\circ} \mathrm{C}$ until needed (33). Soil containing peat moss, perlite, vermiculite, mountain soil, and rice hulls (55:23:15:5:2, \%wt) was partially sterilized on two consecutive days at $60^{\circ} \mathrm{C}$ for $30 \mathrm{~min}$, then infested with $2 \%$ (wt/wt) ground barley grain colonized with Rhizoctonia spp. Healthy, uniform transplants from the three different ages were carefully taken out and individually transplanted into $100 \mathrm{~g}$ of Rhizoctonia-infested soil in 6-cm-diameter plastic pots. Soil adhering to the roots was removed carefully prior to transplant into infested soil.
Soils amended with sterile barley grain served as controls. Pots were covered with black vinyl sheet, incubated at room temperature for $24 \mathrm{~h}$ to stimulate the growth of Rhizoctonia spp., then transferred to the greenhouse (at 28 to $30^{\circ} \mathrm{C}$ ). Disease severity was determined 3 weeks after inoculation by a subjective 0-to-4 scale, where $0=$ healthy, no rot on root and stem; $1=$ light root and stem rot; $2=$ moderate root and stem rot; $3=$ severe root and stem rot; and $4=$ dead plant. A randomized block design with a factorial arrangement of treatments was replicated six times. Data were subjected to twoway analysis of variance (ANOVA) with plant age (3 levels) and isolate (16 total) as factors. Treatment means were separated with Fisher's protected least significant differences (LSD) at $P \leq 0.05$ if interaction between isolate and plant age was not observed (6). Data containing 0 values were transformed to square root before analysis. The experiment was repeated twice. Data from repeated experiments were pooled because there was no

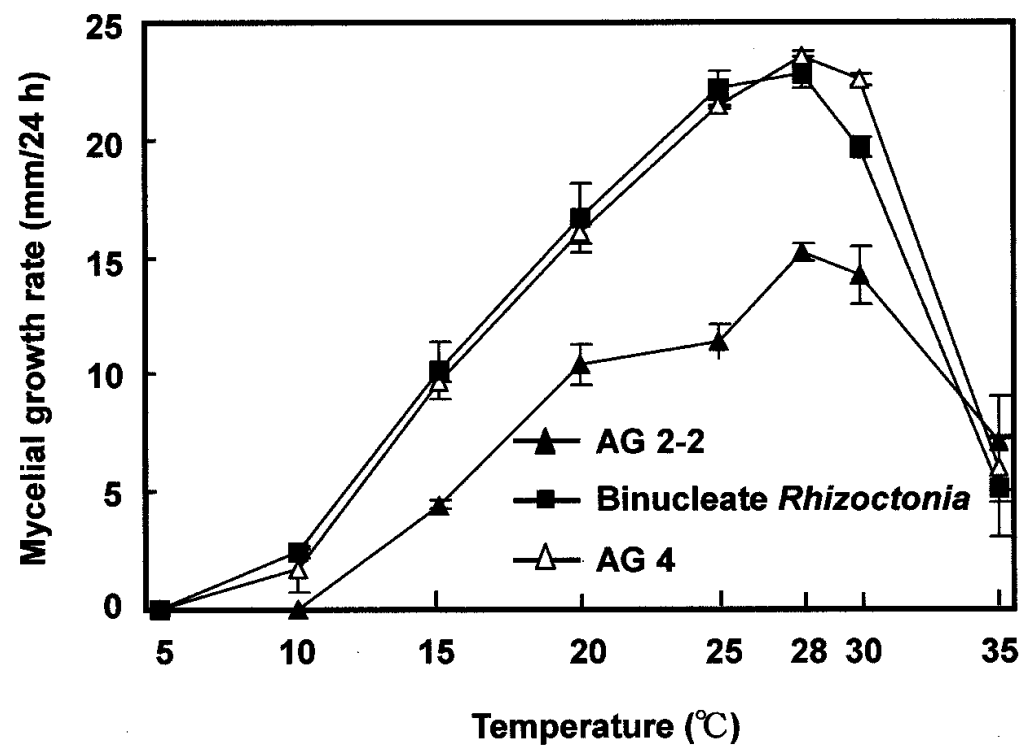

Fig. 2. Effect of various temperatures on mycelial growth rate of Rhizoctonia spp. isolated from miniature roses.

Table 1. Thiamine requirement of Rhizoctonia spp. isolated from miniature roses

\begin{tabular}{lcccc}
\hline & & \multicolumn{2}{c}{ Dry mycelial weight $(\mathbf{m g})$ on the basal medium } \\
\cline { 3 - 5 } Isolate & Rhizoctonia spp. $^{\mathbf{b}}$ & $\mathbf{A}$ & $\mathbf{B}$ & $\mathbf{A}$ : \\
\hline MWR 22 & Binucleate & 265.3 & 285.3 & 0.9 \\
MWR 26 & Binucleate & 253.7 & 259.0 & 1.0 \\
MWR 4 & AG 2-2 & 122.3 & 6.3 & 19.4 \\
MWR 8 & AG 2-2 & 70.7 & 2.7 & 26.2 \\
MWR 32 & AG 2-2 & 174.7 & 8.3 & 21.0 \\
MWR 52 & AG 4 & 54.3 & 57.3 & 0.9 \\
MWR 62 & AG 4 & 46.0 & 44.3 & 1.0 \\
F-1 & AG 1-IC & 67.3 & 68.0 & 1.0 \\
K 2-8 & AG 2-2 IIIB & 148.3 & 2.7 & 55.6 \\
\hline
\end{tabular}

${ }^{\mathrm{a}}$ Glucose asparagine medium used by Ogoshi and Ui (25). A = with thiamine, B = without thiamine. Data are the means of three replicates per isolate.

${ }^{\mathrm{b}}$ Identity of species; binucleate = binucleate Rhizoctonia; AG 1-IC = Rhizoctonia solani AG 1-IC; AG 2-2 = $R$. solani AG 2-2; AG 2-2 IIIB $=R$. solani AG 2-2 IIIB; and AG $4=R$. solani AG 4 .

interaction between experiment and treatment effects.

The virulence of isolates of Rhizoctonia spp. was also determined in assays during rooting of cuttings (pathogenicity test 2 ). Five representative isolates from each group were used. Stems from healthy 45day-old rose plants were cut into 3- to 5$\mathrm{cm}$ lengths, each bearing three to five leaves, and placed in water to prevent dehydration during preparation. Cuttings were planted in 6-cm-diameter plastic pots contained Rhizoctonia-infested soil. Preparation of inoculum and soil was the same as described above. Pots were covered with transparent vinyl and incubated in the greenhouse (at 28 to $30^{\circ} \mathrm{C}$ ). Water was sprayed on the upper surface of the vinyl daily to maintain temperature. Soils amended with sterile barley grain served as controls. Disease severity was determined 2 weeks after inoculation as described above. A randomized block design with isolate as single treatment was replicated five times. Data were subjected to one-way ANOVA. Treatment means were separated with Fisher's protected LSD at $P \leq 0.05$ (6). Data containing 0 values were transformed to square root before analysis. The experiment was repeated twice. Data from repeated experiments were combined because there was no interaction between experiment and treatment effects.

\section{RESULTS}

Isolation and AG determinations. Of 153 Rhizoctonia isolates recovered from diseased roots and stems of roses, 9 had binucleate and 144 had multinucleate vegetative hyphal cells. AG determination revealed that the 144 multinucleate isolates represented AG 2-2 (83.3\%) and AG 4 $(16.7 \%)$. The nine binucleate Rhizoctonia isolates failed to anastomose with tester isolates of AG-A through -S.

Nuclear number. The number of nuclei per cell varied from 3 to 9 and 4 to 15 for isolates of AG 2-2 and AG 4, respectively. All of isolates of binucleate Rhizoctonia contained only two nuclei per hyphal cell.

Colony morphology. The mycelium of isolates of AG 2-2 growing on PDA was white to light tan when young, but became brown to dark brown with age. Concentric rings of light and dark mycelium were apparent. Sclerotia were abundantly produced. Isolates of AG 2-2 grown on Czapek agar produced few sclerotia and concentric ring growth was not visible (data not shown). The mycelium of isolates of AG 4 was white to light tan when young, but became light to dark brown and brown to dark brown with age on PDA and Czapek agar, respectively. Sclerotia were 2 to $4 \mathrm{~mm}$ in diameter and changed from light brown to brown with age. Isolates of binucleate Rhizoctonia formed sclerotia 0.5 to $3 \mathrm{~mm}$ in diameter and changed from brown to dark brown color with age. Concentric rings of dark and light mycelium 
were visible in isolates of binucleate Rhizoctonia grown on PDA but not on Czapek agar (data not shown).

Hyphal growth rates. Hyphal growth rates of isolates of binucleate Rhizoctonia and $R$. solani AG 4 were similar except at $30^{\circ} \mathrm{C}$ (Fig. 2). Isolates of binucleate Rhizoctonia and $\mathrm{AG} 4$ grew at $10^{\circ} \mathrm{C}$, had an optimum growth rate at $28^{\circ} \mathrm{C}$, and had the ability to grow at $35^{\circ} \mathrm{C}$. Isolates of $\mathrm{AG}$ 2-2 did not grow at 5 and $10^{\circ} \mathrm{C}$; however, these isolates also had an optimal temperature at $28^{\circ} \mathrm{C}$ and could grow as well at $35^{\circ} \mathrm{C}$ as isolates of binucleate Rhizoctonia and $\mathrm{AG} 4$.

Thiamine requirement. Isolates of binucleate Rhizoctonia and AG 4 grew at approximately the same rate in basal medium with or without thiamine, indicating thiamine prototrophy (Table 1). Isolates of AG 2-2 grew about 20 times faster in basal medium with thiamine than in basal me- dium without thiamine (thiamine auxotrophic) (Table 1). Anastomosis tester isolates of AG 1-IC and AG 2-2 IIIB were confirmed to be thiamine prototrophic and auxotrophic, respectively.

RFLP of rDNA-ITS. Restriction enzymes HinfI and HincII digested isolates of AG 4 obtained from roses and produced the same banding patterns characteristic of the isolate of AG 4 HG-I R97 (Fig. 3). The isolate of AG 4 HG-II Rh131 was not digested using the same enzymes. Restriction enzymes HinfI and HincII produced four and three fragments, respectively, on isolates of AG 4 obtained from miniature roses as well as the isolate of AG 4 HG-I R97. Neither restriction enzyme HinfI nor HincII produced restriction site on isolate of AG 4 HG-II Rh131.

Pathogenicity study. In pathogenicity test 1 , isolates of binucleate Rhizoctonia caused severe root and stem rot and

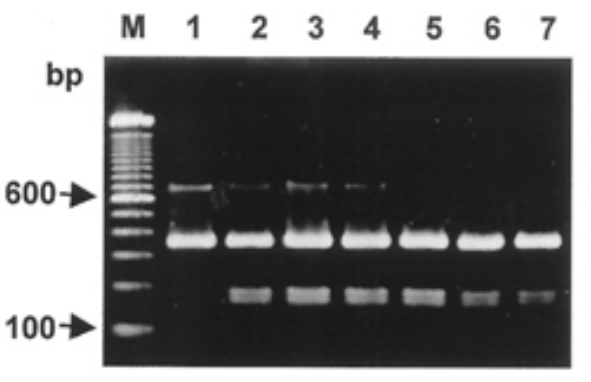

Hinfl

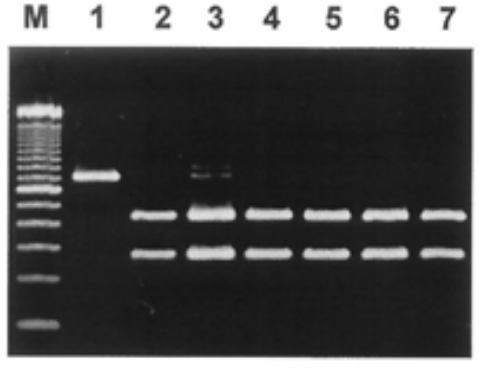

Hincll
Fig. 3. DNA restriction digest patterns of the ribosomal DNA-internal transcribed spacer region of Rhizoctonia solani AG 4 using endonucleases HinfI and HincII. Lane designations: M = 100-bp ladder; 1 = isolate of AG 4 HG-II Rh131; 2 = isolate of AG 4 HG-I R97; 3 to 7 = isolates of MWR 52, MWR 56, MWR 62, MWR 65, and MWR 67, respectively, obtained from miniature roses. mortality on 15-old-day but not on 25- or 40-old-day plants. Isolates of $R$. solani AG 2-2 caused severe root and stem rot and mortality on 15- and 25-old-day plants but light root rot on 40-old-day plants. In contrast to isolates of binucleate Rhizoctonia and AG 2-2, isolates of AG 4 caused severe root and stem rot and mortality on 15-, 25-, and 40-old-day plants. No disease was observed on control treatments (Table 2). Rhizoctonia spp. were reisolated from diseased tissue plants completing Koch's postulates. ANOVA indicated that isolate and plant age were highly significant factors $(P=0.001)$ in disease severity index of miniature rose cv. Silk. There also was a significant interaction between isolate and plant age $(P=0.001)$.

In pathogenicity test 2 , all isolates of binucleate Rhizoctonia, AG 2-2, and AG 4 caused severe rot on cuttings during rooting showing severe damage (disease severity index $=4$ ). Differences in disease severity ratings among isolates were not significant (data not shown). At 4 to 7 days after inoculation, rot symptoms began to appear first on lower stems, then on upper stems of cuttings. Leaves also were infected as disease development progressed. Mortality occurred as roots were not formed and plants declined. No disease was observed on control treatments.

\section{DISCUSSION}

Binucleate Rhizoctonia and multinucleate $R$. solani AG 2-2 and AG 4 were isolated from diseased roots and stems of miniature roses. Isolates of binucleate Rhizoctonia failed to anastomose with the tester isolates of AG-A through AG-S (not included were AG-J and AG-M). Although

Table 2. Pathogenicity of 15 isolates of Rhizoctonia spp. to three plant ages of miniature rose cv. Silk ${ }^{\mathrm{a}}$

\begin{tabular}{|c|c|c|c|c|c|c|c|c|c|}
\hline \multirow[b]{2}{*}{ Isolate } & \multicolumn{3}{|c|}{15 days old } & \multicolumn{3}{|c|}{25 days old } & \multicolumn{3}{|c|}{40 days old } \\
\hline & Root $\operatorname{rot}^{\mathbf{b}}$ & Stem rot ${ }^{c}$ & Severity $^{d}$ & Root rot & Stem rot & Severity & Root rot & Stem rot & Severity \\
\hline \multicolumn{10}{|c|}{ Rhizoctonia Binucleate } \\
\hline MWR 20 & + & + & 4 & - & - & 0 & - & - & 0 \\
\hline MWR 21 & + & + & 4 & - & - & 0 & - & - & 0 \\
\hline MWR 22 & + & + & 4 & - & - & 0 & - & - & 0 \\
\hline MWR 24 & + & + & 4 & - & - & 0 & - & - & 0 \\
\hline MWR 26 & + & + & 4 & - & - & 0 & - & - & 0 \\
\hline \multicolumn{10}{|c|}{ R. solani AG 2-2 IIIB } \\
\hline MWR 4 & + & + & 4 & + & + & 4 & + & - & 1 \\
\hline MWR 6 & + & + & 4 & + & + & 4 & + & - & 1 \\
\hline MWR 8 & + & + & 4 & + & + & 4 & + & - & 1 \\
\hline MWR 16 & + & + & 4 & + & + & 4 & + & - & 1 \\
\hline MWR 32 & + & + & 4 & + & + & 4 & + & - & 1 \\
\hline \multicolumn{10}{|c|}{ R. solani AG 4 HG-I } \\
\hline MWR 52 & + & + & 4 & + & + & 4 & + & + & 4 \\
\hline MWR 56 & + & + & 4 & + & + & 4 & + & + & 4 \\
\hline MWR 59 & + & + & 4 & + & + & 4 & + & + & 4 \\
\hline MWR 62 & + & + & 4 & + & + & 4 & + & + & 4 \\
\hline MWR 69 & + & + & 4 & + & + & 4 & + & + & 4 \\
\hline
\end{tabular}

a Age of transplants of miniature rose plants after 6 weeks of rooting.

b Dark brown or black with decay of roots after inoculation with Rhizoctonia-infested soil mix. Symptoms were observed 3 weeks after inoculation. Pots were incubated at 28 to $30^{\circ} \mathrm{C}$ in the greenhouse; + and - = presence and absence of rot symptom, respectively.

${ }^{c}$ Dark brown or black with dry rot of stems after inoculation with Rhizoctonia-infested soil mix. Symptoms were observed 3 weeks after inoculation. Pots were incubated at 28 to $30^{\circ} \mathrm{C}$ in the greenhouse; + and $-=$ presence and absence of rot symptom, respectively.

d Disease severity: plants were scored for disease 3 weeks after inoculation using a subjective scale of 0 to 4 , where $0=$ healthy plants and $4=$ plants dead. Values are the means of six replicate miniature rose plants per isolate. 
tester isolates of AG-J and AG-M were not used in anastomosis determination, we believe that isolates of binucleate Rhizoctonia obtained from miniature roses differ with AG-J and AG-M, especially in their pathogenicity. Isolates of AG-J cause diseases on bean, pea, radish, onion, lettuce, tomato, soybean, cowpea, and peanut. Isolates of AG-M have not been reported to be plant pathogens (29). Martin (19) observed inconsistent assessment of AG for binucleate Rhizoctonia recovered from strawberry. Some strawberry isolates did not anastomose with the tester isolate, although the RFLP banding patterns suggested that they were in the same AG with the tester isolate. Therefore, more than one AG tester isolate is needed for inferring that isolates of binucleate Rhizoctonia obtained from miniature roses represent a new group. Additionally, molecular analysis would be helpful to characterize and identify isolates of binucleate Rhizoctonia (28).

Our observations that isolates of AG 2-2 had an optimum growth rate at $28^{\circ} \mathrm{C}$ are similar to the results of studies on isolates of AG 2-2 obtained from soybean (18) and bentgrass (13). The ability of these isolates to grow at $35^{\circ} \mathrm{C}$ and their auxotrophism for thiamine further suggested that isolates of AG 2-2 obtained from miniature roses belong to ecological type IIIB (AG 2-2 IIIB). Neither isolate AG 2-2 IV nor AG 2$2 \mathrm{LP}$ has been reported to grow at $35^{\circ} \mathrm{C}$. In addition, colony morphology on PDA confirmed that isolates of $A G$ 2-2 obtained from miniature roses belong to AG 2-2 IIIB (29).

Isolates of AG 4 HG-I and AG-4 HG-II are not differentiated by anastomosis frequency but by DNA base sequence homology (16). On the RFLP of rDNA-ITS using restriction enzymes HinfI and HincII, isolates of $\mathrm{AG} 4$ obtained from miniature roses had similar banding patterns with isolate of AG 4 HG-I R97 obtained from sugar beet. Isolates of AG 4 HG-II Rh131 obtained from sugar beet had no restriction site when digested with HinfI or HincII. Similar results using restriction enzyme HincII on isolates of AG 4 was reported by Keijer et al. (14). Our results strongly suggest that isolates of AG 4 obtained from miniature roses belong to subgroup HG-I (AG 4 HG-I).

Pathogenicity tests revealed that isolates of binucleate Rhizoctonia, $R$. solani AG 22 IIIB, and AG 4 HG-I are causal pathogens of root and stem rot of miniature rose. The evidence that all tested isolates could cause severe damage on rose during rooting suggested that much attention should be paid during this stage of production. For miniature rose propagation, most commercial growers use the method employed in this study.

Isolates of AG 4 are more virulent than those of AG 2-2 IIIB and binucleate Rhizoctonia. Isolates of binucleate Rhizoc- tonia are much less virulent than isolates of AG 2-2 IIIB. As reported by other investigators, pathogenicity of Rhizoctonia spp. is host dependent. Trujillo et al. (32) reported that isolates of AG 2-2 were more virulent than AG 4 on carnation. On potato, isolates of AG 3 were more virulent than AG 5 and AG 8 (9). Isolates of $R$. solani AG 4 were generally more virulent on beet seedlings compared to isolates of AG 2.

Host age influences virulence of $R$. solani on sugar beet (10). Our observations that young miniature roses are more susceptible than older plants are compatible with the apparent disease progression observed in the field.

To our knowledge, this is the first detailed report of root and stem rot disease of miniature rose caused by binucleate Rhizoctonia, R. solani AG 2-2 IIIB, and AG 4 HG-I. Further field studies are needed on the ecology and pathogenicity of Rhizoctonia spp. to formulate steps for controlling root and stem rot of miniature rose.

\section{ACKNOWLEDGMENTS}

A. Priyatmojo thanks the Ministry of Education, Science, Sports, and Culture (Monbusho) Japan for financial assistance; and we thank S. S. Kantha, Gifu University, Gifu Japan for critical reading of the manuscript.

\section{LITERATURE CITED}

1. Adams, G. C. 1988. Thanatephorus сисиmeris (Rhizoctonia solani) a species complex of wide host range. Pages 535-552 in: Advances in Plant Pathology. Vol 6, Genetics of Plant Pathogenic Fungi. G. S. Sidhu, ed. Academic Press, New York.

2. Andersen, T. F., and Rasmussen, H. N. 1996. The mycorrhizal species of Rhizoctonia. Pages 379-390 in: Rhizoctonia Species: Taxonomy, Molecular Biology, Ecology, Pathology, and Disease Control. B. Sneh, S. JabajiHare, S. Neate, and G. Dijst, eds. Kluwer Academic Publishers, Dordrecht, the Netherlands.

3. Anderson, N. A. 1982. The genetics and pathology of Rhizoctonia solani. Annu. Rev. Phytopathol. 20:329-344.

4. Bandoni, R. J. 1979. Safranin O as a rapid nuclear stain for fungi. Mycologia 71:873-874.

5. Benson, D. M., and Cartwright, D. K. 1996. Ornamental diseases incited by Rhizoctonia spp. Pages 303-314 in: Rhizoctonia Species: Taxonomy, Molecular Biology, Ecology, Pathology, and Disease Control. B. Sneh, S. Jabaji-Hare, S. Neate, and G. Dijst, eds. Kluwer Academic Publishers, Dordrecht, the Netherlands.

6. Campbell, R. C. 1989. Statistics for Biologists, 3rd ed. Cambridge University Press, Cambridge, UK.

7. Carling, D. E. 1996. Grouping in Rhizoctonia solani by hyphal anastomosis reaction. Pages 37-47 in: Rhizoctonia Species: Taxonomy, Molecular Biology, Ecology, Pathology, and Disease Control. B. Sneh, S. Jabaji-Hare, S. Neate, and G. Dijst, eds. Kluwer Academic Publishers, Dordrecht, the Netherlands.

8. Carling, D. E., Baird, R. E., Kuninaga, S., and Gitaitis, R. D. 1999. Characterization of anastomosis group (AG) 13 of Rhizoctonia solani. (Abstr.) Phytopathology 89:S11.

9. Carling, D. E., and Leiner, R. H. 1990. Virulence of isolates of Rhizoctonia solani AG 3 collected from potato plant organs and soil.
Plant Dis. 74:901-903.

10. Herr, L. J. 1996. Sugar beet diseases incited by Rhizoctonia spp. Pages $341-350$ in: Rhizoctonia Species: Taxonomy, Molecular Biology, Ecology, Pathology, and Disease Control. B. Sneh, S. Jabaji-Hare, S. Neate, and G. Dijst, eds. Kluwer Academic Publishers, Dordrecht, the Netherlands

11. Hietela, A. M., Sen, R., and Lilja, A. 1994. Anamorphic and teleomorphic characteristics of uninucleate Rhizoctonia sp. isolated from the roots of nursery grown conifer seedlings. Mycol. Res. 98:1044-1050.

12. Horst, R. K. 1983. Compendium of Rose Diseases. The American Phytopathological Society, St. Paul, MN

13. Hyakumachi, M., Mushika, T., Ogiso, Y., Toda, T., Kageyama, K., and Tsuge, T. 1998. Characterization of a new cultural type (LP) of Rhizoctonia solani AG 2-2 isolated from warm-season turfgrasses, and its genetic differentiation from other cultural types. Plant Pathol. 47:1-9.

14. Keijer, J., Houterman, P. M., Dullemans, A M., and. Korsman, M. G. 1996. Heterogeneity in electrophoretic karyotype within and between anastomosis groups of Rhizoctonia solani. Mycol. Res. 100:789-797.

15. Kronland, W. C., and Stanghellini, M. E. 1988. Clean slide technique for the observation of anastomosis and nuclear condition of Rhizoctonia solani. Phytopathology 78:820822.

16. Kuninaga, S., and Yokosawa, R. 1984. DNA base sequence homology in Rhizoctonia solani Kühn. IV. Genetic relatedness within AG 4. Ann. Phytopathol. Soc. Jpn. 50:322-330.

17. Lee, S. B., and Taylor, J. W. 1990. Isolation of DNA from fungal mycelia and single spores. Pages 282-287 in: PCR protocols: A Guide to Methods and Applications. M. A. Innis, D. H. Gelfand, J. J. Sninsky, and T. J. White, eds. Academic Press, New York

18. Liu, Z., and Sinclair, J. B. 1991. Isolates of Rhizoctonia solani anastomosis group 2-2 pathogenic to soybean. Plant Dis. 75:682-687.

19. Martin, F. N. 2000. Rhizoctonia spp. recovered from strawberry roots in Central Coastal California. Phytopathology 90:345-353.

20. Menzeis, J. D. 1970. Introduction: the first century of Rhizoctonia solani. Pages 3-5 in: Biology and Pathology of Rhizoctonia solani. J. R. Parmeter, Jr., ed. University of California Press, Berkeley.

21. Ogoshi, A. 1987. Ecology and pathogenicity of anastomosis and intraspecific groups of Rhizoctonia solani Kühn. Annu. Rev. Phytopathol. 25:125-143.

22. Ogoshi, A., Oniki, M., Araki, T., and Ui, T. 1983. Anastomosis groups of binucleate Rhizoctonia in Japan and North America and their perfect states. Trans. Mycol. Soc. Jpn 24:79-87.

23. Ogoshi, A., Oniki, M., Araki, T., and Ui, T. 1983. Studies on the anastomosis groups of binucleate Rhizoctonia and their perfect states. J. Fac. Agric. Hokkaido Univ. 61:244260.

24. Ogoshi, A., Oniki, M., Sakai, R., and Ui, T. 1979. Anastomosis grouping among isolates of binucleate Rhizoctonia. Trans. Mycol. Soc. Jpn. 20:33-39.

25. Ogoshi, A., and Ui, T. 1979. Specificity in vitamin requirement among anastomosis groups of Rhizoctonia solani Kühn. Ann Phytopathol. Soc. Jpn. 45:47-53.

26. Parmeter, J. R., Jr., and Whitney, H. S. 1970. Taxonomy and nomenclature at the imperfect state. Pages 7-19 in: Biology and Pathology of Rhizoctonia solani. J. R. Parmeter, Jr., ed. University of California Press, Berkeley.

27. Priyatmojo, A., Yotani, Y., Hattori, K. Kageyama, K., and Hyakumachi, M. 1999. 
Root and stem rot caused by Rhizoctonia spp. on rose growing in glasshouse in Gifu prefecture. (Abstr.) Ann. Phytopathol. Soc. Jpn. 65:408.

28. Salazar, O., Julian, M. C., and Rubio, V. 2000. Primers based on specific rDNA-ITS sequences for PCR detection of Rhizoctonia solani, R. solani AG 2 subgroups and ecological types, and binucleate Rhizoctonia. Mycol. Res. 104:281-285.

29. Sneh, B., Burpee, L., and Ogoshi, A. 1991. Identification of Rhizoctonia Species. The American Phytopathological Society Press, St. Paul, MN.
30. Stevens-Johnk, J., and Jones, R. K. 1994. Comparisons of whole-cell fatty acid compositions in intraspecific groups of Rhizoctonia solani AG-1. Phytopathology 84:271-275.

31. Toda, T., Hyakumachi, M., Suga, H., Kageyama, K., Tanaka, A., and Tani, T. 1999. Differentiation of Rhizoctonia AG-D isolates from turfgrass into subgroups I and II based on rDNA and RAPD analyses. Eur. J. Plant Pathol. 105: 835-846.

32. Trujillo, E. E., Shimabuku, R., Cavin, C. A., and Aragaki, M. 1988. Rhizoctonia solani anastomosis groupings in carnation fields and their pathogenicity to carnation. Plant Dis.
72:863-865.

33. Villajuan-Abgona, R., Kageyama, K., and Hyakumachi, M. 1996. Biocontrol of Rhizoc tonia damping-off of cucumber by nonpathogenic binucleate Rhizoctonia. Eur. J. Plant Pathol. 102:227-235.

34. White, T. J., Bruns, T., Lee, S. B., and Taylor, J. 1990. Amplification and direct sequencing of fungal ribosomal RNA genes for phylogenetics. Pages 315-322 in: PCR Protocols: A Guide to Methods and Applications. M. A. Innis, D. H. Gelfand, J. J. Sninsky, and T. J. White, eds. Academic Press. New York. 